\title{
The L-shaped modification of the transverse upper gracilis (TUG) flap
}

\author{
Juan Enrique Berner ${ }^{1,2} \cdot$ John M. D. Henton ${ }^{3} \cdot$ Adam Blackburn $^{1}$ \\ Received: 4 February 2020 / Accepted: 24 March 2020 / Published online: 11 April 2020 \\ (C) The Author(s) 2020
}

\begin{abstract}
A variety of free tissue flaps have been described for autologous breast reconstruction. Although the deep inferior epigastric perforator (DIEP) flap is most microsurgeons' first choice, there is no consensus regarding which is the second-best alternative. The transverse upper gracilis (TUG) flap has gained popularity for cases where the abdomen is not a suitable donor site. This musculocutaneous flap has the advantage of an easy dissection, allowing the harvest of tissue from the medial thigh area with the patient supine. However, drawbacks include a tedious donor site closure and a limited amount of soft tissue that can be transferred. The authors hereby present a modification of the TUG flap, introducing an L-shaped skin paddle: the L-shaped upper gracilis (LUG) flap. This alternative allows harvesting extra tissue from the medial thigh, while providing an easier donor site closure with the patient supine. A prospective case series of 14 LUG flaps is presented. No flap failures or episodes of fat necrosis were encountered; only one developed a donor site seroma that settled after drainage. The LUG flap is a useful development of the TUG flap concept providing up to 50\% more tissue than a standard TUG flap with an aesthetically pleasing donor site closure which is useful for cases in which abdominal flaps are not possible.

Level of evidence: Level IV, therapeutic study.
\end{abstract}

Keywords Reconstructive surgical procedures $\cdot$ Free tissue flaps $\cdot$ Microsurgery $\cdot$ Mammaplasty

\section{Introduction}

The Queen Victoria Hospital, East Grinstead has seen increasing numbers of women choosing breast reconstruction with autologous tissue following mastectomy $[1,2]$. The reasons for this are probably multifactorial: national guidelines stating that all forms of reconstruction should be discussed with patients irrespective of local availability [3], better patient access to information and "show and tell" sessions where patients can meet others who have undergone reconstruction.

This project was presented in the 10th Congress of the World Society of Reconstructive Microsurgery (WSRM) in Bologna, Italy on the 14th of June 2019.

Juan Enrique Berner

juan.berner@nhs.net

1 Queen Victoria Hospital NHS Foundation Trust, Holtye Road, East Grinstead, UK

2 Kellogg College, University of Oxford, Oxford, UK

3 Newcastle Upon Tyne Hospitals NHS Foundation Trust, Newcastle, UK
Increasing concerns regarding implant-based reconstruction, due to reports of anaplastic large cell lymphoma (ALCL), and higher than anticipated failure and complication rates [4], along with apprehensions about the longterm durability of implants have also played a role. For all of these reasons, patients who were not traditionally seen as good autologous tissue reconstruction candidates, due to slim bodily habitus and lack of donor tissue, are now presenting for autologous breast reconstruction. This has led to increasing complexity of reconstruction procedures with more frequent bipedicled deep inferior epigastric perforator (DIEP) flaps, stacked flaps and alternative donor sites.

While breast reconstruction with an abdominal based free flap is widely accepted as the gold standard, this is not possible in all patients. Our preferred alternative to the DIEP flap is to use tissue from the medial thigh, such as the transverse upper gracilis (TUG) flap $[5,6]$. We consider that the TUG has several benefits over buttock flaps, in that the tissue has a similar consistency to a native breast, it can be raised with the patient supine, the donor site scar is well hidden and that it can be raised relatively quickly. Potential disadvantages of the TUG flap are 
potential pedicle size mismatch compared recipient vessels, tight donor site closure, limited flap volume and risk of damage to the posterior cutaneous nerve of the thigh during harvest [7].

In order to address some of these issues, the TUG flap skin paddle design has been modified by some authors, by changing its orientation. These variations, the diagonal/ oblique upper gracilis (DUG) [8] and vertical upper gracilis (VUG) flaps [9], avoid placing a scar on the posterior thigh and ease the closure of the donor site, but do not offer a substantial increase in the overall flap volume which can be harvested.

Our modification of the thigh flap utilizes the principles of cosmetic thigh lifting to produce a flap which is well vascularized from the musculocutaneous perforators from the gracilis. This allows an increased volume of both fat and skin for transfer while recontours the thigh leaving a scar similar to the extended vertical thigh lift [10]. Furthermore, the posterior cutaneous nerve of the thigh is unlikely to be damaged during the flap raise and the scar does not extend onto the posterior thigh. We call this musculocutaneous Lshaped upper gracilis (LUG) flap.

\section{Materials and methods}

A prospective study was undertaken of patients undergoing breast reconstruction using the LUG flap at our institution from the 1st of September 2018 to the 30th of August 2019. This project was approved by our Trust Audit Department and was not deemed to require ethical approval as the flap is based on established techniques. This work is compliant with national data protection regulations and STROBE guidelines [11]. Demographic information, technical details and postoperative complications were recorded, and patient consent for publication was obtained.

\section{Flap harvest}

The LUG flap intends to maintain the donor site advantages of the DUG flap, while increasing the amount of harvested tissue. It resembles the TUG design on its lateral aspect, with an anterior transverse limb parallel to the groin crease. The crease itself is lined by skin and very little subcutaneous tissues; therefore, an incision slightly inferior to it is preferred, leaving fascial attachments to the crease intact.

Over the gracilis muscle, the shape of the skin paddle curves inferiorly taking a vertical disposition (Fig. 1). We start raising this flap on the lateral border of the transverse limb, keeping the dissection plane at the level of the Scarpa's fascia while lateral to the great saphenous vein, thus avoiding inadvertent harvest of lymphatic tissue

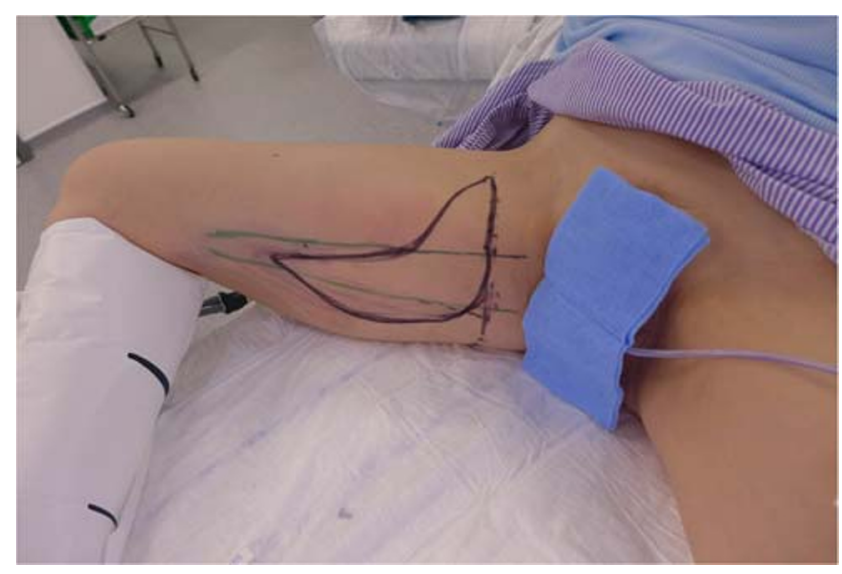

Fig. 1 Design of the LUG flap with its skin paddle marked in black, while the course of the underlying gracilis muscle is marked in green

(Fig. 2). Once medial to the great saphenous, the plane of dissection deepens, reaching the fascia over the adductor longus (Fig. 3). Once the gracilis muscle is reached, it is advisable to leave its fascia intact to avoid inadvertent shearing of the skin paddle. The anterior margin of this flap is limited by the position of the great saphenous vein, while the posterior border runs along the posterior border of the gracilis. Once the skin paddle has been raised, the gracilis muscle dissection proceeds in the standard fashion (Fig. 4).

The flap is then detached and transferred to the chest (Fig. 5). For gracilis-based flaps, we routinely use the internal mammary vessels and access is gained by removing the fourth rib. At the fourth interspace, caliber of the internal mammary vessels is similar to the gracilis pedicle, meaning size mismatch is not usually a problem.

Following microsurgical anastomosis, the L-shaped paddle is secured resting across the medial, inferior and

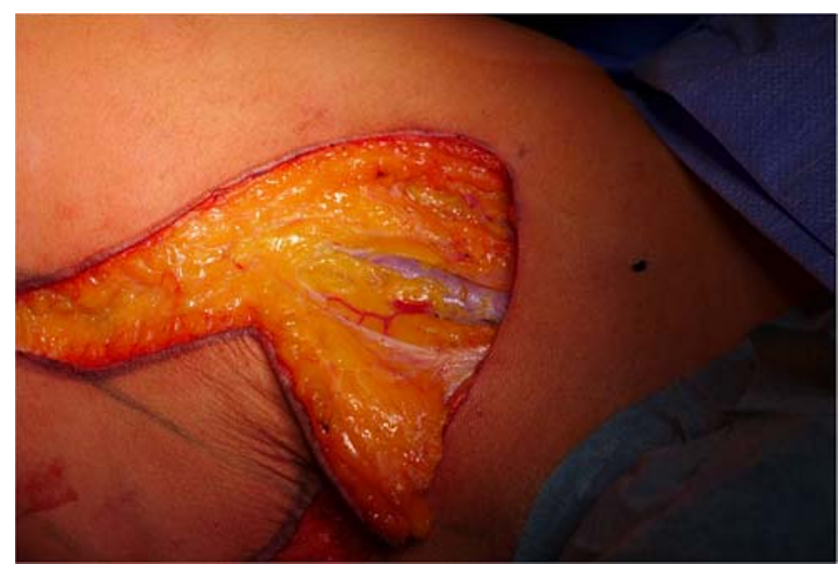

Fig. 2 Raising of the LUG flap. Initial dissection of the lateral edge of the skin paddle, superficial to the great saphenous vein to avoid inadvertently harvesting lymphatic tissue 


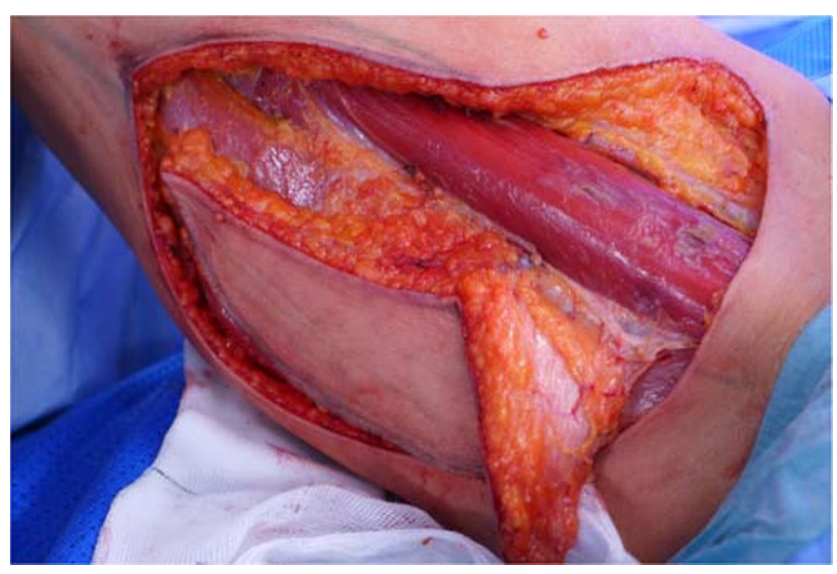

Fig. 3 Medial to the great saphenous vein the raising of the paddle moves to a deeper plane, including the adductor longus fascia

lower poles. The gracilis muscle is placed vertically providing upper pole fullness.

\section{Results}

Over the 12-month study period, a total of 14 LUG flaps for 11 patients were performed. Seven of these individuals required an immediate unilateral breast reconstruction for breast cancer (Fig. 6); two patients had BRCA-1 gene mutation and underwent immediate reconstructions for bilateral riskreducing mastectomies (Fig. 7); and two patients with a previous implant-based reconstruction underwent a salvage procedure with a LUG flap. Recovery for this small cohort of patients was uneventful, with no flap failures. On average, patients were discharged from the hospital on post-operative day 2 . None of these patients presented donor site dehiscence

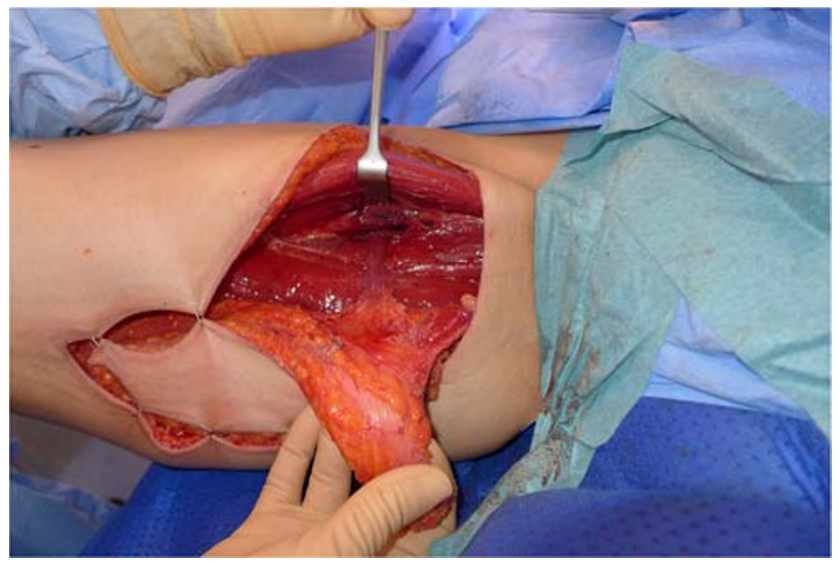

Fig. 4 Fascia over the gracilis muscle is preserved and the rest of the skin paddle can be incised, islanding the flap. This is followed by dissection of the vascular pedicle or infective complications following discharge. Only one patient required drainage of a thigh seroma which took 2 weeks to resolve (Table 1).

\section{Discussion}

The LUG flap modification addresses one of the most important limitations attributed to the traditional TUG flap: it provides an increased volume of tissue, while improving the closure of the donor site. An extensive area of contact between the fasciocutaneous paddle and the underlying muscle allows reliable perfusion, and we have not encountered any cases of fat necrosis. It is even easier to inset, as its L-shape facilitates coning of the flap to enhance projection. For one particular patient, we performed a LUG and a TUG flap for one breast, allowing us to compare the harvested volumes between these two flaps. We were surprised that the LUG flap was $50 \%$ heavier than the TUG flap for a single patient.

Our design could be considered a modification of the "vertical-transverse" design of the TUG flap proposed by SaintCyr et al. [12], but there are two main differences. The transverse limb of the design reported in this article is anterior to the gracilis muscle, rather than posterior. This has the advantage of providing a comfortable closure of the donor site, reducing the risk of harming the posterior cutaneous nerve of the thigh and avoiding a scar on the gluteal crease. This allows patients to sit up earlier in their recovery, without the discomfort associated with the traditional TUG flap or its other modifications. We also believe that the tissue from the anterior transverse limb, which is soft and thin, provides a better match for reconstruction of the medial fullness of the breast.

The profunda artery perforator (PAP) flap is another alternative for harvesting tissue from the medial thigh. This fasciocutaneous flap avoids taking the gracilis muscle.

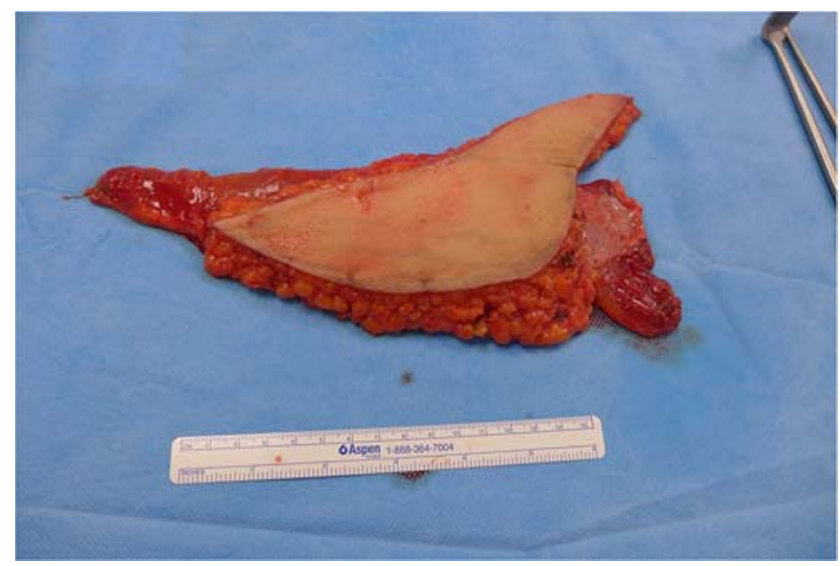

Fig. 5 A detached L-shaped gracilis flap. Flap is laid on surgical table just before transfer to chest 
However, the gracilis is generally considered to be expendable and, in our experience, the gracilis muscle is able to contribute to the overall reconstruction volume in thin patients with limited donor sites. Despite secondary muscle atrophy, the remaining muscle provides some residual volume and is a well vascularized recipient for subsequent fat grafting to further enhance the definitive cosmetic outcome.

The small number of patients included in this series somewhat limits the external validity of our results, along with the fact that we have not yet used it for delayed breast reconstruction after a simple mastectomy. The DIEP flap is still our first choice for breast reconstruction, usually providing generous amounts of skin and soft tissue and a relatively long vascular pedicle. However, we believe that the LUG design is a safe alternative for patients seeking autologous breast reconstruction where the abdomen is not a suitable donor site. A larger case series would be able to prove this concept. In our practice, it has already found its place within our reconstructive armamentarium.
Fig. 6 A 49-year-old patient underwent an immediate left breast reconstruction with a right LUG flap. a Pre-operative photograph. b Six-month post-operative photograph. c Final result after nipple reconstruction and nipple-areola complex tattooing
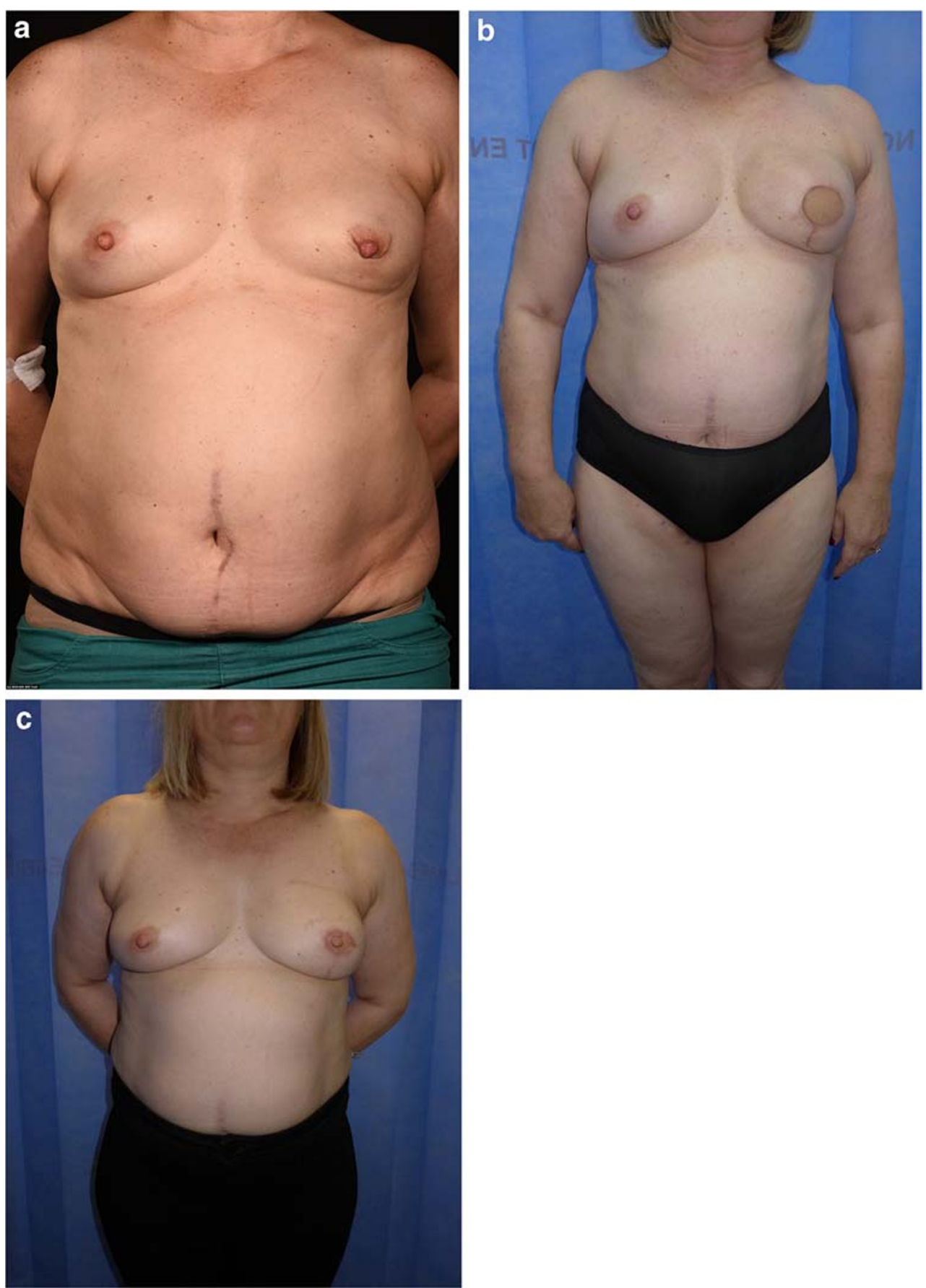

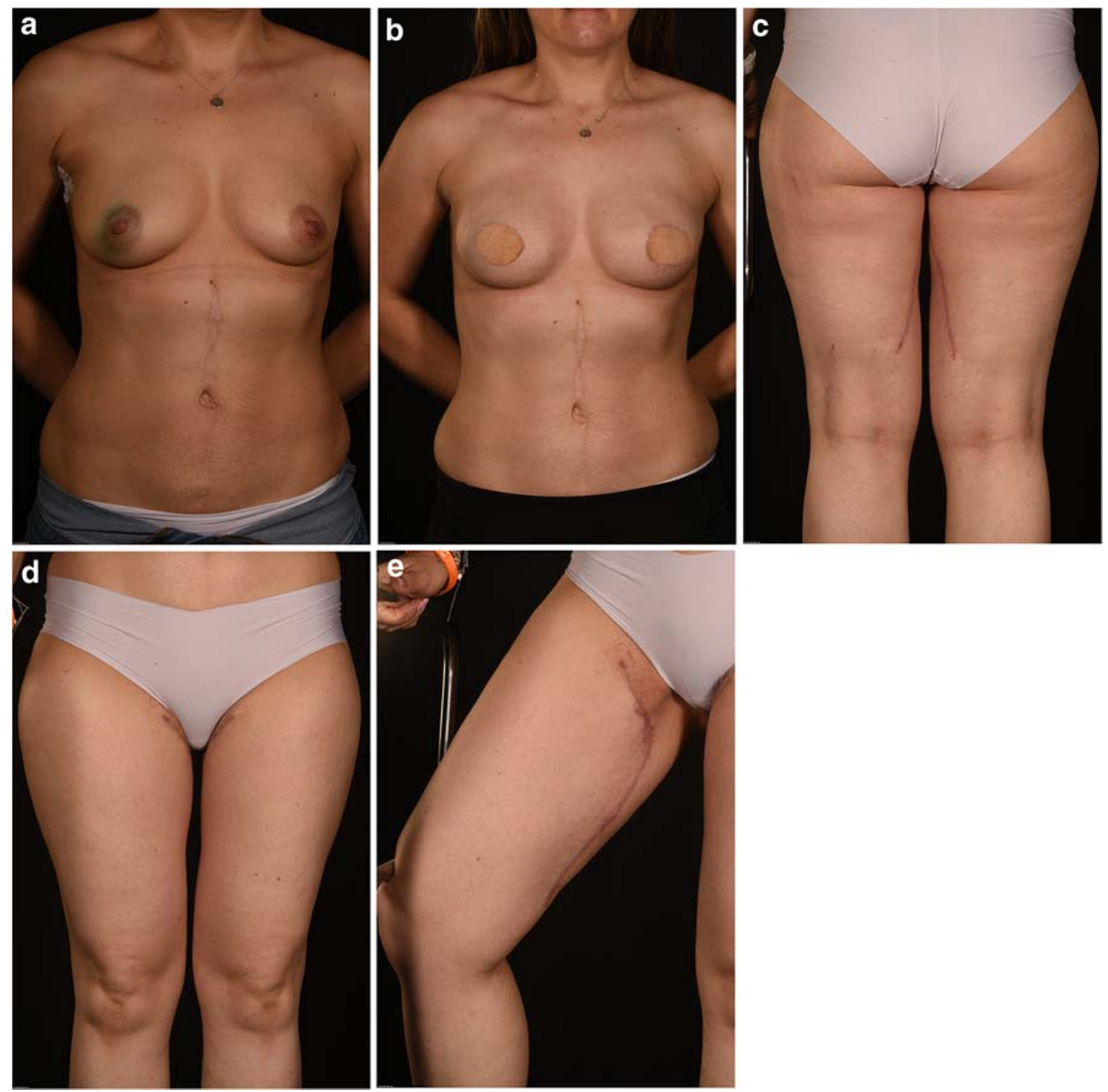

Fig. 7 A 35-year-old patient, BRCA-1 gene carrier, had a bilateral risk-reducing mastectomy and reconstruction with LUG flaps. a Pre-operative photograph. b Post-operative photographs after 3 months. c-e Donor site scars on anterior, posterior and medial thigh views

Table 1 Case series of L-shaped upper gracilis (LUG) flaps including 11 patients and 14 free flaps

\begin{tabular}{|c|c|c|c|c|c|}
\hline & Age & Timing of reconstruction & $\begin{array}{l}\text { Unilateral/ } \\
\text { bilateral }\end{array}$ & Comments & Complications \\
\hline 1 & 59 & Immediate & Left unilateral & Right LUG flap: $510 \mathrm{~g}$ & Donor site seroma \\
\hline 2 & 65 & Immediate delayed (previous implant-based reconstruction) & Left unilateral & & Nil \\
\hline 3 & 49 & Immediate & Left unilateral & & Nil \\
\hline 4 & 40 & Immediate (BRCA-1 gene carrier) & Bilateral & Right LUG flap: 508 g/left LUG flap: $512 \mathrm{~g}$ & Nil \\
\hline 5 & 70 & Immediate & Right unilateral & Left LUG flap: $214 \mathrm{~g}$ & Nil \\
\hline 6 & 39 & Immediate & Right unilateral & Left LUG flap: $273 \mathrm{~g}$ & Stitch abscess \\
\hline 7 & 45 & Immediate & Right unilateral & & Nil \\
\hline 8 & 34 & Immediate & Left unilateral & Left TUG flap: $170 \mathrm{~g}$ / Right LUG flap: $240 \mathrm{~g}$ & Nil \\
\hline 9 & 35 & Immediate & Bilateral & $\begin{array}{l}\text { Left LUG flap: } 376 \\
\text { Right LUG flap: } 380\end{array}$ & Nil \\
\hline 10 & 48 & Immediate (BRCA-1 gene carrier) & Bilateral & & Nil \\
\hline 11 & 52 & Immediate delayed (previous implant-based reconstruction) & Unilateral & Left LUG flap: $360 \mathrm{~g}$ & Nil \\
\hline
\end{tabular}


Funding information This study was funded entirely by its authors.

\section{Compliance with ethical standards}

This project was approved by our Trust Audit Department and was not deemed to require ethical approval as the flap is based on established techniques. This work is compliant with national data protection regulations and STROBE guidelines [11]. Demographic information, technical details and post-operative complications were recorded, and patient consent for publication was obtained.

Conflict of interest Juan Enrique Berner, John M. D. Henton and Adam Blackburn deny any conflicts of interests.

Ethical approval This study was prospectively approved by the Queen Victoria Hospital Audit and Quality Improvement Department.

Informed consent The patients whose photographs have been included in this study have signed a consent form as per our Hospital protocol and were contacted to confirm this prior to publication.

Open Access This article is licensed under a Creative Commons Attribution 4.0 International License, which permits use, sharing, adaptation, distribution and reproduction in any medium or format, as long as you give appropriate credit to the original author(s) and the source, provide a link to the Creative Commons licence, and indicate if changes were made. The images or other third party material in this article are included in the article's Creative Commons licence, unless indicated otherwise in a credit line to the material. If material is not included in the article's Creative Commons licence and your intended use is not permitted by statutory regulation or exceeds the permitted use, you will need to obtain permission directly from the copyright holder. To view a copy of this licence, visit http://creativecommons.org/licenses/by/4.0/.

\section{References}

1. Moller L et al (2019) The reconstructive journey: description of the breast reconstruction pathway in a high-volume UK-based microsurgical centre. J Plast Reconstr Aesthet Surg 72(12):1930-1935
2. Henton J, Berner JE, Blackburn A, Molina A (2020) Microsurgical training opportunities at the Queen Victoria Hospital. Ann Plast Surg 00:1

3. Recommendations | Early and locally advanced breast cancer: diagnosis and management | Guidance | NICE n.d. https://www.nice. org.uk/guidance/ng101/chapter/Recommendations\#breastreconstruction. Accessed February 4, 2020

4. Potter S, Conroy EJ, Cutress RI, Williamson PR, Whisker L, Thrush S, Skillman J, Barnes NLP, Mylvaganam S, Teasdale E, Jain A, Gardiner MD, Blazeby JM, Holcombe C, iBRA Steering Group., Breast Reconstruction Research Collaborative (2019) Short-term safety outcomes of mastectomy and immediate implant-based breast reconstruction with and without mesh (iBRA): a multicentre, prospective cohort study. Lancet Oncol 20: 254-266

5. Arnez ZM, Pogorelec D, Planinsek F, Ahcan U (2004) Breast reconstruction by the free transverse gracilis (TUG) flap. Br J Plast Surg 57:20-26

6. Locke MB, Zhong T, Mureau MAM, Hofer SOP (2012) Tug 'O' war: challenges of transverse upper gracilis (TUG) myocutaneous free flap breast reconstruction. J Plast Reconstr Aesthetic Surg 65: 1041-1050

7. Saour S, Libondi G, Ramakrishnan V (2017) Microsurgical refinements with the use of internal mammary (IM) perforators as recipient vessels in transverse upper gracilis (TUG) autologous breast reconstruction. Gland Surg 6:375-379

8. Dayan E, Smith ML, Sultan M, Samson W, Dayan JH (2013) The diagonal upper gracilis (DUG) flap. Plast Reconstr Surg 132:33-34

9. Park JE, Alkureishi LWT, Song DH (2015) TUGs into VUGs and friendly BUGs. Plast Reconstr Surg 136:447-454

10. Capella JF (2014) The vertical medial thigh lift. Clin Plast Surg 41: 727-743

11. von Elm E, Altman DG, Egger M, Pocock SJ, Gøtzsche PC, Vandenbroucke JP et al (2007) The Strengthening the Reporting of Observational Studies in Epidemiology (STROBE) statement: guidelines for reporting observational studies. Lancet 370:14531457

12. Saint-Cyr M, Wong C, Oni G, Maia M, Trussler A, Mojallal A et al (2012) Modifications to extend the transverse upper gracilis flap in breast reconstruction. Plast Reconstr Surg 129:24e-36e

Publisher's note Springer Nature remains neutral with regard to jurisdictional claims in published maps and institutional affiliations. 